\title{
Recursos de ciències al portal edu365.com
}

\author{
M. Lluïsa Abad Roses \\ Projectes TIC per a l'Educació, Departament d'Educació \\ mabad1@xtec.cat
}

El portal educatiu edu365.com ofereix a la comunitat educativa recursos que potencien l'autoaprenentatge $i$ afavoreixen el treball col/laboratiu. Es tracta d'una bona col.lecció de materials instructius, accés a enciclopèdies $i$ diaris per a estudiants, espai a la xarxa per publicar treballs, canals de comunicació com el servei de consultoria, el correu electrònic $i$ els xats i la possibilitat de formar grups de treball virtuals a través d'educampus.

L'edu365.com és un portal del Departament d'Educació de la Generalitat de Catalunya orientat i desenvolupat per a l'alumnat i les seves famílies i que proporciona al professorat un conjunt de recursos (materials instructius, eines i serveis) que el poden ajudar en el desenvolupament de la tasca educativa.

La major part dels recursos són d'accés lliure, només alguns serveis, com la consultoria o el correu electrònic, i l'accés a diccionaris i enciclopèdies, estan restringits per a usuaris registrats.

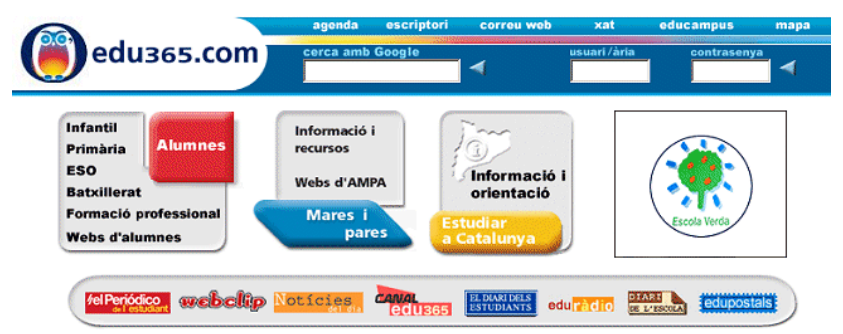

Figura 1. Portada de l'edu365.com des d'on s'accedeix a les pàgines dels diferents nivells educatius, a l'escriptori, a l'edició web de diaris per a estudiants, a educampus...

Des de la portada s'accedeix al correu web i al $x a t$, dos serveis que poden utilitzar-se en el desenvolupament de treballs de grup i permeten incorporar a l'aula procediments $\mathrm{i}$ hàbits de comunicació habituals a la societat actual.

També des de la portada es pot accedir a diaris per a estudiants. És el cas de El diari de l'estudiant, en el qual, a part de les notícies diàries, es poden trobar recursos sobre temes de ciències i tecnolo- gia. Un altre cas és el del Diari de l'escola, servei de notícies d'actualitat elaborat per Vilaweb, amb articles redactats i adreçats específicament als alumnes dels centres educatius. La lectura i anàlisi de notícies i articles de diari a l'aula és una bona estratègia per contextualitzar els continguts de ciències.

\section{LES PÀGINES DE PRIMÀRIA I ESO}

Les pàgines de primària $\mathrm{i}$ ESO ofereixen una bona col-lecció de materials multimèdia $\mathrm{i}$ interactius elaborats per mestres i professors que afavoreixen l'autonomia i el protagonisme de l'alumne en el procés d'aprenentatge. És el cas de les unitats didàctiques amb les seves activitats d'aprenentatge i avaluació, les activitats JClic amb exercicis d'identificació i relació i els vídeos que es poden visionar en línia o es poden descarregar al disc dur de l'ordinador.

\section{Les miniunitats didàctiques}

Uns materials molt interessants són les mini unitats didàctiques (MUD), materials d'autoaprenentatge que pretenen donar resposta a un o més aspectes d'algun contingut curricular.

Cada MUD té un o diversos apartats en els quals els continguts es desenvolupen de forma contextualitzada. Es parteix d'exemples concrets pròxims a l'alumnat, o que en despertin la curiositat, per arribar a la descripció d'un fenomen o a l'enunciat, més abstracte, d'una llei.

Aquests apartats s'han desenvolupat mitjançant aplicacions interactives de manera que l'alumne pot 
treballar de manera autònoma i d'acord amb el seu propi ritme d'aprenentatge. A l'aula, el professor o la professora pot atendre un o altre alumne, mentre la resta del grup treballa sol.

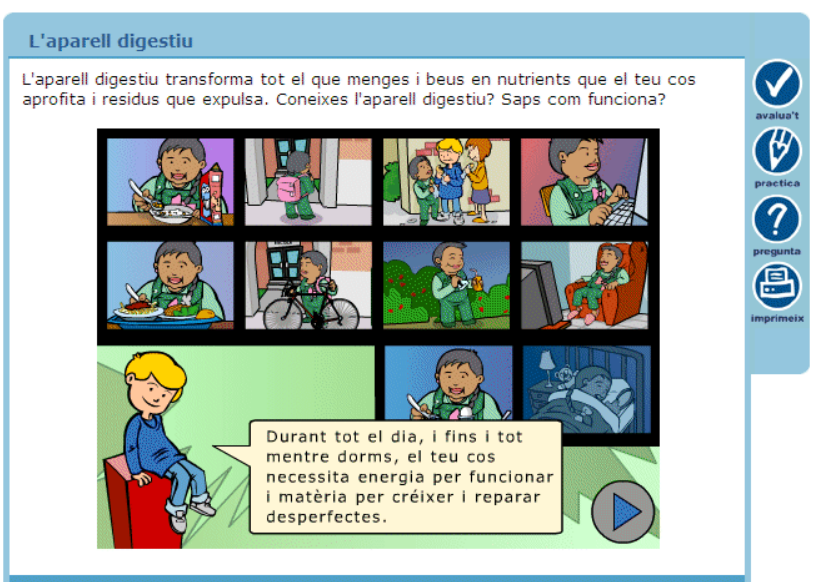

Figura 2: Imatge d'una MUD amb l'accés als apartats avalua't i practica. Des de pregunta s'accedeix directament a la consultoria.

L'avalua't és un apartat d'autoavaluació. A través d'un qüestionari o d'un exercici d'arrossegar s'avalua la capacitat de l'alumnat d'identificar i relacionar els continguts introduiits a l'apartat informatiu. També es pot utilitzar com a exercici d'avaluació inicial.

El practica conté una o més propostes de treball que permeten desenvolupar la capacitat d'aplicar i analitzar els continguts tractats. De vegades hi trobareu una experiència que es pot dur a terme amb material d'ús domèstic, un document per completar i imprimir, una col-lecció de problemes, la visita a una pàgina web amb l'objectiu de cercar i analitzar informació...

El practica està plantejat de manera que els alumnes el poden realitzar a l'aula d'informàtica, a l'aula del grup o a casa, sense necessitat d'entrar al laboratori. Es tracta d'afavorir la dinàmica de classe i evitar que a la mateixa hora un sol grup necessit dos espais tan sol-licitats com l'aula d'informàtica i el laboratori.

Les MUD més complexes, també disposen d'un glossari amb vocabulari i imatges dels continguts tractats.

Des d'aquí es pot accedir a la llista completa de MUD de primària i de secundària.

Un altre tipus de material són les preguntes amb resposta que pretenen donar una resposta curta i aclaridora a alguna qüestió d'interès. La majoria inclou un o més enllaços a pàgines web relacionades amb el tema. Algunes d'elles s'han elaborat recollint consultes plantejades per l'alumnat en el servei de consultoria del portal.

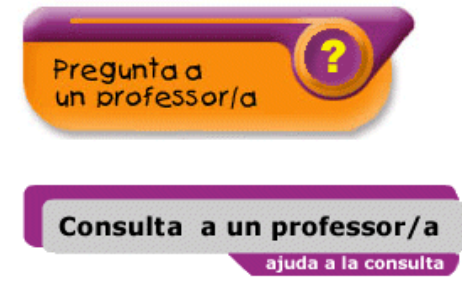

Figura 3: Icones de l'accés al servei de consultoria amb professors i professores especialistes en les diverses matèries. Per accedir-hi, cal ser usuari/a donat d'alta al portal.

\section{Primària}

A la pàgina de primària també s'hi pot trobar $\underline{E l}$ món per un forat, que presenta una sèrie de vídeos amb àudio, acompanyats de fotografies i activitats interactives pensats per al treball d'observació indirecta dins l'entorn natural i social. Està estructurat en tres grans blocs: éssers vius, paisatge i societat $\mathrm{i}$ va adreçat a l'alumnat de cicle inicial.

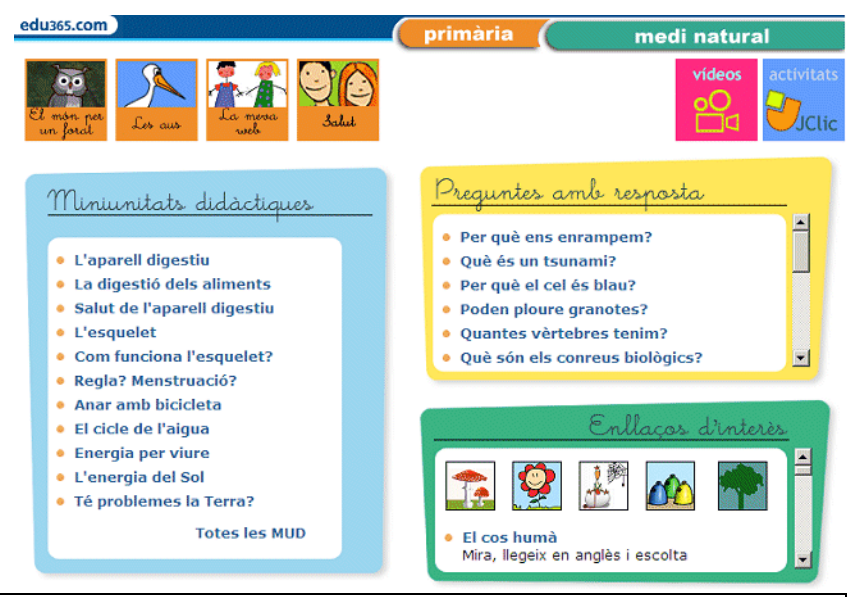

Figura 4: Portada de la pàgina de coneixement del medi natural de primària. $A$ la pàgina si pot trobar una interessant selecció d'enllaços d'interès.

\section{Secundària Obligatòria}

A la pàgina d'ESO hi ha alguns materials dissenyats i elaborats exclusivament per a aquesta etapa educativa.

Aquest any, física! és un recull d'experiments de física, en forma de fitxes, que es van publicar durant l'any 2005. Cada fitxa conté imatges de l'experiment en forma de vídeo, fotografies o dibuixos, la relació del material necessari i els passos a seguir per reproduir-lo. A més a més, es fan unes preguntes per incentivar la interpretació i l'anàlisi del fenomen observat. 
El Laboratori virtual reprodueix un laboratori escolar amb prestatgeries on es troba distribuït l'utillatge. Es pot navegar per l'escenari i donar la volta completa al laboratori. Un clic sobre l'utillatge i s'obre una fitxa informativa. A les parets s'hi troba la farmaciola, l'extintor i un pòster amb els pictogrames de perillositat. Un clic i s'obté informació sobre el contingut imprescindible de la farmaciola i com actuar en cas d'accident, una selecció de normes bàsiques de seguretat i informació sobre el significat dels pictogrames de perillositat dels productes químics. La imatge de la taula periòdica està enllaçada a una unitat didàctica sobre el tema. També ofereix una col-lecció d'activitats d'autoaprenentatge i avaluació.

Es tracta d'un laboratori de química digital l'objectiu del qual és facilitar la preparació de les activitats experimentals de química.

Exercicis i problemes ofereix col-leccions de problemes de física i química. Una petita introducció per recordar els conceptes bàsics, una sèrie de problemes amb la seva solució i la resolució pas a pas, i uns exercicis d'autoavaluació amb aclariments en els missatges d'error i encert.

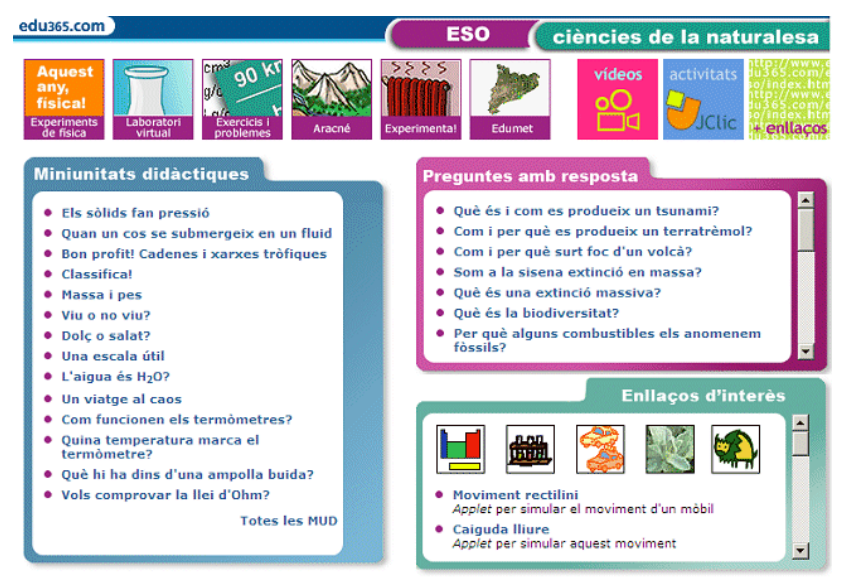

Figura 5: Portada de la pàgina de ciències de la naturalesa d'ESO. Els apartats enllaços d'interès i + enllaços contenen interactius, simuladors i propostes multimèdia de professionals de l'educació i d'institucions.

Uns materials més complets són els publicats amb els títols d'Aracné i Experimenta i que desenvolupen els continguts de ciències naturals i de física i química de $1 r$ cicle d'ESO, respectivament. Cada unitat s'inicia amb una animació i es va desenvolupant a través de textos, imatges, animacions i exercicis interactius. Els termes del vocabulari enllacen a un glossari a través d'hipertext. Totes dues aplicacions disposen d'una guia didàctica per al professorat i són materials molt adequats per a un seguiment del curs a través d'Internet, com pot ser el cas d'alumnat d'educació a distància o d'aules hospitalàries. Per accedir-hi s'ha de tenir identificador XTEC o edu365.

\section{LA PÀGINA DE BATXILLERAT}

La unitat de projectes TIC per a la Educació té previst preparar una pàgina de ciències per a batxillerat, però de moment el portal edu365.com ofereix materials per ajudar l'alumnat de ciències en la cerca d'informació i orientar-lo en l'elaboració del treball de recerca. És el cas dels Recursos en xarxa, una selecció de pàgines d'interès classificades per matèries: biologia, ciències de la Terra i del medi ambient, física i química.

També és el cas del Laboratori interdisciplinar que, a més a més, fa propostes de temes i ofereix ajut per a la realització del treball de recerca a través de tutories virtuals.

Com fer un treball de recerca és un altre d'aquest recursos amb pautes, exemples i una plantilla per a la presentació escrita.

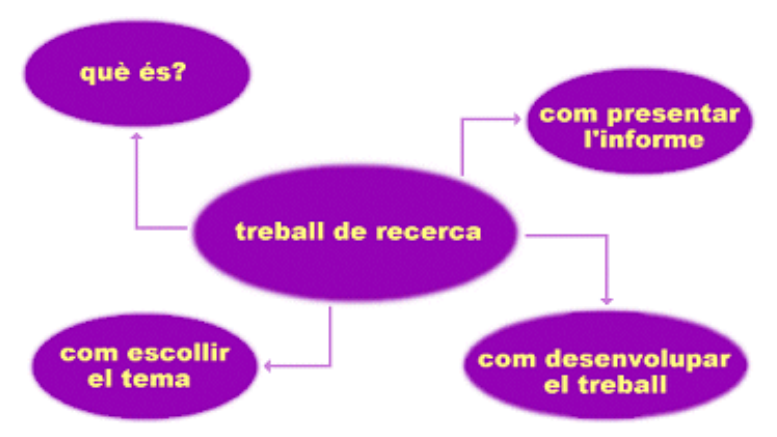

Figura 6: Imatge de la pàgina Com fer un treball de recerca.

\section{L'ESCRIPTORI DIGITAL}

Des de l'escriptori es pot accedir a La Hiperenciclopèdia de la Gran Enciclopèdia Catalana, a Enciclonet i a la Encyclopaedia Britannica que, a més a més, ofereix vídeos, animacions i materials d'aprenentatge de ciències en llengua anglesa. Són eines molt útils en la cerca d'informació.

També es pot accedir a l'editor i a les carpetes per a l'elaboració de documents i publicació de treballs, respectivament.

L'editor és una eina que permet escriure documents en línia en format RTF i desar-los a la carpeta personal. 


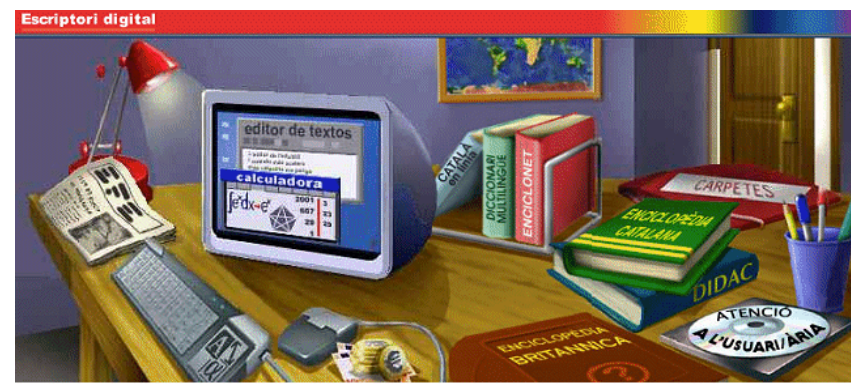

Figura 7. L'escriptori digital amb les enciclopèdies, l'editor, la calculadora i les carpetes personals.

Les carpetes són l'espai personal dels usuaris a la xarxa. El portal disposa d'un administrador per a la gestió de les carpetes a la xarxa que permet desar i recuperar documents des de qualsevol ordinador connectat a Internet. Cada usuari disposa de 15 Mb d'espai. La secció Webs d'alumnes, a la qual s'hi accedeix des de la portada, recull una selecció de pàgines elaborades per alumnes amb identificador edu365. Pot ser un estímul per a l'elaboració i publicació de treballs en format web.

\section{EDUCAMPUS}

L'educampus és un entorn de treball en línia que facilita diverses situacions d'aprenentatge i treball col-laboratiu. Permet la formació de grups virtuals entre alumnes d'un grup classe, d'un centre o de diversos centres per a realitzar activitats (quaderns virtuals, activitats JClic, visites a pàgines web...), participar en fòrums o intercanviar materials.

L'entorn també permet fer grups de professors per compartir materials, dinamitzar activitats o per a cursos de formació. Hi poden accedir des de la portada de l'edu365 tots els usuaris XTEC i edu365 registrats.

\section{EN RESUM}

El portal edu365.com ofereix diversos tipus de recursos. Alguns d'aquests recursos, com són la majoria dels materials didàctics, resulten molt útils en la preparació de programacions flexibles que potencien l'autoaprenentage i respectin els diferents ritmes d'aprenentage dels alumnes. Altres, com els serveis i l'ús que es faci de les eines, potencien la creativitat i el treball cooperatiu entre els membres d'un grup i són un bon suport per al desenvolupament de les capacitats personals i col-lectives dels alumnes.

\section{WEBS}

- Portal educatiu edu365.com http://www.edu365.com

- Informació i presentació de recursos de l'edu365.com http://www.xtec.es/formaciotic/edu365

- Recursos de ciències a l'edu365 i a la XTEC http://www.xtec.es/ mabad1/recursosciencies

\section{BIBLIOGRAFIA}

Domènech, J. (2005). Aprendiendo en red. Aula de Innovación Educativa,142, pp. 51-54.

Marin, B. (2005). Uso inteligente de las TIC: una ocasión para cambiar la metodología. Aula de Innovación Educativa, 143-144, pp. 69-71.

Martín, J.M.; Beltrán, J.A.; Pérez, L. (2003). Cómo aprender con Internet. Madrid: Fundación Encuentro.

Sala, M.; Fonoll, J. (2005). El profesor o profesora, capitán de navío en un mar de recursos (Internet). Aula de Innovación Educativa, 139, pp. 49-52. 